\title{
Superintendent Evaluations: School Boards Report on Criteria, Procedures, and Professional Development
}

\author{
Nicole V. Williams \\ University of Findlay \\ Kerry Robinson \\ University of North Carolina Wilmington \\ John C. Gillham \\ University of Findlay \\ Kristie Fetty \\ University of Findlay
}

The purpose of this study was to investigate how school boards evaluate superintendents in two different states. The researchers created a questionnaire that consisted of 35 questions in three areas based on the research topics: superintendent evaluation criteria, superintendent evaluation procedures, and school board professional development. Seventy-six school board members participated in the study. Ninety percent of participant school boards are required to evaluate their superintendent. However, only 26 percent of participants reported they utilize the Professional Standards for Educational Leaders (2015) to evaluate the superintendent. The participants also reported a variety of procedures are utilized to evaluate the superintendent. Ninety percent are also not required to receive training to evaluate a superintendent.

Keywords: superintendent, school boards, evaluations, professional development

\section{INTRODUCTION}

The role of the superintendent is critical in determining the direction and success of a school district. "Superintendents must be able to assume multiple roles within the organization to accomplish the varied goals and objectives" (Tienken, 2021, p. 1). It is the responsibility of the school board to evaluate how the superintendent is meeting these goals and objectives in each of their respective districts. The purpose of this study was to investigate how school boards evaluate their superintendents in two different states. Despite the wealth of literature existing on the value of district leadership and its influence on the overall success of the district, comparatively neglected is literature on superintendent evaluation. The evaluation of superintendents is a unique process compared to other educational positions. "Superintendents are the only school system employees not supervised or evaluated by another licensed professional. Yet superintendents must be evaluated" (DiPaola et al., 2019, p. 25). Traditionally, responsibilities of the 
superintendents have served as the basis for evaluation criteria. These responsibilities are communicated to superintendents upon hiring and described within "a generalized [job] description that often is loosely related to actual job responsibilities and even more loosely connected to the superintendent's performance evaluation" (DiPaola \& Stronge, 2001, p. 98). School boards are then challenged and pledged as elected citizens to develop and implement a robust system for superintendent evaluation.

Currently, there are not broadly adopted, uniform guidelines for how the superintendent, the key implementer of federal, state, and local policy at the district level, is to be evaluated. Although the superintendent is the only educational leader appointed by a board of citizens elected by the public, "school board members are not required to have a background or specialized knowledge of education" (Schneider, 2018, p. 9). Weber (2007) found that many school board members don't understand the responsibilities associated with the superintendent position, therefore finding it difficult to conduct a proper evaluation. DiPaola (2007) found that the lack of understanding of educational responsibilities of the superintendent has led many school boards, "to hurriedly conduct the superintendent evaluation in an attempt to satisfy a legal requirement" (p. 2). While the majority of states now require superintendent policies in the U.S., there are still approximately one-third of the country that does not have a state-level policy (DiPaola et al., 2019).

Goens (2009) described how the lack of a clearly defined evaluation process leads school boards to turn to the superintendent for direction on how to conduct their own evaluation. Kowalski, et al. (2011) found most superintendents were evaluated upon a set of criteria developed between the school board and the superintendent. While a majority of superintendents agreed to the criteria, only a small minority of superintendents reported the criteria aligned to any actual performance standards. Mayo and McCartney (2004) reported superintendents felt the "agreed upon terms" lacked many essential characteristics of an evaluation such as relevancy, data-driven measures, consistency, and clarity. Finnan et al. (2015) found that superintendents relied on interpreting their school board members' views to guide their performance choices and the "agreed upon terms" for the evaluations. To further complicate the process, Finnan et al. (2015) also noted the complexity of the constantly changing "agreed upon terms" in light of the turnover of school board members after each election.

The purpose of this study was to investigate how school boards evaluate the superintendent in two states. Research on the superintendent is minimal when compared to research on teachers and principals and even less scholarship has been devoted to the criteria and processes associated with superintendent evaluation. The research questions that guided this study included: 1.) What criteria do school boards use to evaluate superintendents? 2.) What procedures do school boards use to evaluate superintendents? 3.) What professional development do school boards use to learn how to evaluate superintendents? 4.) How do school boards use the superintendent evaluation?

\section{LITERATURE REVIEW}

School board members usually hire superintendents based on personal characteristics (Cleveland et. al, 2000), and school boards typically evaluate the superintendent based on criteria not directly related to job performance (Bell, 2019). Superintendents themselves believe they are evaluated on personal characteristics and not their job descriptions (Glass et al., 2000). Findings from other studies confirm many superintendents are evaluated more on their relationship with school board members and personal traits (Bridges et al., 2019; Glass et al., 2000; Jackson, 2016; Melton et al., 2019; Yates \& Jong, 2018). In Maranto et al.'s (2017) analysis of 115 superintendent contracts, school boards put more emphasis on superintendent relationships with the school board and outside stakeholders and politics rather than the historically managerial tasks often associated with the position. The emphasis on relationships and politics even outweighed the instructional oversights emphasized by both the Every Student Succeeds Act (ESSA) and No Child Left Behind (NCLB) goals (Robinson \& Shakeshaft, 2016). Contract language further revealed a superintendent's job security often rested in the working relationship with the school board.

Cleveland et al. (2000) conducted a descriptive study to determine what processes and factors determined the evaluation of superintendents in Illinois, Missouri, and Texas. Specifically, the research questions investigated the development of the evaluation system, district policies, current trends, actual 
practices of superintendent evaluations, participation of stakeholders in the evaluation process, and the types of instruments used to guide the process. One hundred thirty-eight superintendents across the three states responded to their Likert-based survey. Data showed that $95 \%$ of superintendents reported their school district had a formal evaluation since it is required by law in two of the three states at the time this study took place. Ninety-nine percent of evaluations were reported to be conducted by school board members in a closed session. Only $66 \%$ of the superintendents reported they felt their evaluation procedures were fair. This study also examined how often the evaluations occurred. Eighty-three percent stated they were evaluated annually, even though $68 \%$ were on a contract length of two to three years. In all three states, $63 \%$ of superintendents reported their evaluations were conducted in the form of a checklist or rating scale completed by the board members. While superintendents were the primary developers of criteria in some states, in all states combined $84 \%$ of the process and development of the instrument was by the board members. Among these superintendents, 56\% felt they had an influence in the design of the evaluation instrument. A limitation to this study was that the sampling techniques contained errors and did not capture a true representation of districts across all states in relation to the size of each state.

In another study conducted in the same year, Glass et al. (2000) created one of the largest comprehensive surveys of the American superintendent at the time. Among the many compelling findings was that school boards frequently receive their training for how to evaluate superintendents from the superintendents themselves. Of the $70 \%$ of superintendents who reported being evaluated by board members, only $15 \%$ reported school boards provide an orientation to newly elected members. A majority (73.6\%) of superintendents reported being a major stakeholder in training school board members and $46.2 \%$ of superintendents stated the training they provided was the only training given to new board members. Most of these superintendents felt their school boards were less than well-qualified and superintendents reported they had to be involved or even implement the new school board member training.

DiPaola and Stronge (2001) conducted a two-phase content analysis study of the criteria state departments of education recommended to school boards, and what frameworks or instruments superintendent associations recommended for use in superintendent evaluation. Data were collected from publicly available information and from documents requested from state departments of education. The researchers also examined the National School Boards Association (NSBA) and the American Association of School Administrators (AASA) criteria for superintendent evaluation. The results of the study showed only Texas, Hawaii, and Oregon (6\%) fully matched the criteria for superintendent evaluations recommended by both the state department of education and AASA. Forty-two states (84\%) had partial alignment, but the results varied greatly in the types of alignment in criteria. Finally, there were five states that did not utilize or have any related language tied to the recommendations from AASA. Further analysis of the 42 states' variations in language related to AASA recommendations highlighted organizational management (88\%) was the most common standard recommended by state departments to school districts. The least common occurring standard in recommendations from state departments was values and ethics of leadership. DiPaola and Stronge (2001) found that the most commonly recommended instruments from state departments covered criteria on management objectives in the form of a printed rating scale. The researchers highlighted that printed rating scales worked well to clarify expectations, characteristics of the job, were easy to use, and were comprehensive. State departments also recommended one model to conduct the evaluation through the use of a printed rating scale, leaving the superintendent with minimal feedback and support for professional growth. State department recommendations provided no sound criteria or tools of evaluation to school boards. State departments were also not fully recommending researched-based developed standards by educators in the field, such as from AASA. Despite the work of AASA and the Joint Committee on Standards for Educational Evaluations (JCSEE), only three of the 50 states (6\%) recommended fully following those standards developed by educators.

As a follow-up to the DiPaola and Stronge (2001) study, DiPaola et al., (2019) conducted a comprehensive policy analysis of superintendent evaluation across all 50 states. This study examined all factors that influence and inform the policy process including the criteria and procedures state departments recommend to school districts. The 2019 study found that 34 states (67 percent) adopted evaluation policies instead of simply general recommendations, a significant increase over the five states (ten percent) that had 
such policies in 2000 . However, there were still 17 states (34\%) that had no actual policy for superintendent evaluation and only five states $(10 \%)$ required the use of a reporting and tracking system for completed superintendent evaluations. An analysis of the 17 states (34\%) without policies revealed no connections or commonalities to explain why they lacked an evaluation policy. Schneider (2018) noted that even though the superintendent is critical to school success, three years after the passage of ESSA, approximately a third of the states in America still did not have a superintendent evaluation policy. Even in the case of the states that did have policies, there was a wide variation in the alignment between the JCSEE Standards and the superintendent evaluation policy (DiPaola et al., 2019).

Henrikson (2018) posited that superintendent evaluation is problematic due to school board governance remaining outside the daily operations of school. This is especially concerning when it is suggested superintendents use as much as $40-50 \%$ of their time cultivating relationships and providing professional development material to the board of education (Bell, 2019). Superintendents are asked to provide those that evaluate them with the knowledge base with which they are to be evaluated. In Jackson's (2016) case study of two school districts, both superintendent participants noted the importance of educating the board of education. Board member participants all agreed they rely on the superintendent and feel it's part of the superintendent's job to educate new board members about the school system and how education works. One superintendent participant even signed board members up for trainings and lead book studies about political and social changes in education reform. This supports the issue across professions that elected political officials such as school board members are not fully prepared to make equitable and evaluative decisions for the school district and leadership team without the help of those in the profession. Although utilizing standards for superintendent evaluation has started to become more common, superintendent perceptions of their confidence in respect to these standards as well as how accurate and effective the standards measure their professional practice have been minimally researched.

\section{METHODS}

The purpose of this study was to investigate how school boards evaluate the superintendent in two states. Research on the superintendent is minimal when compared to research on teachers and principals and even less scholarship has been devoted to the criteria and processes associated with superintendent evaluation. The research questions that guided this study included: 1.) What criteria do school boards use to evaluate superintendents? 2.) What procedures do school boards use to evaluate superintendents? 3.) What professional development do school boards use to learn how to evaluate superintendents? 4.) How do school boards use the superintendent evaluation?

To answer the research questions, the researchers utilized mixed methods survey research to support the necessity of quantitative data and qualitative data. The School Board Evaluations of Superintendents questionnaire consisted of 35 questions (open-ended, yes/no/not applicable, multiple choice, and selected response) in three sections based on the research questions: Superintendent Evaluation Criteria, Superintendent Evaluation Procedures, and School Board Professional Development. The questionnaire was designed based on the National Policy Board for Educational Administration (NPBEA) Professional Standards for Educational Leaders (2015), the Joint Committee on Standards for Educational Evaluation (JCSEE) Personnel Evaluation Standards (2009), and current literature on superintendent evaluation.

To answer the first research question, participants were asked if they evaluate their superintendent, and if so, what criteria is used. The questions on criteria included the use of the Professional Standards for Educational Leaders (2015), use of any state-developed standards, or use of the superintendent job description in the evaluation. The data collected from the questionnaire for the second research question was based on the Personnel Evaluation Standards (2009) including data sources used, how data are collected, document review, performance goals, rating scales, timelines, frequency, and outside facilitators. To answer the third research question, the participants were asked questions focused on the type, frequency, training, and topics of the school board professional development for the purpose of evaluation of the superintendent. Finally, to answer the final question, the participants were simply asked how they utilize the superintendent evaluations. 
The questionnaire also included a brief demographics section to collect general participant data: state, tenure, role, number of school board members, number of women on the school board, school board member race, school board member background in education, term limit, length of time participant has been on the school board, school board member participation in the superintendent evaluation, district type, number of students, school board association membership, and National School Boards Association membership.

Quantitative data analyses were conducted through the computation of descriptive statistics (means, standard deviation, and frequencies) to calculate the overall response reported for each question and the demographic information. ANOVAs were conducted to determine variance across demographic groups. Cronbach's Alpha values were calculated to check factor score reliability. The criteria subscale consisted of 14 items $(\boldsymbol{\alpha}=.82)$, the procedures subscale consisted of 5 items $(\boldsymbol{\alpha}=.83)$, and the professional subscale consisted of 2 items $(\boldsymbol{\alpha}=.92)$. The Cronbach's Alpha levels represent a good internal consistency. Qualitative data analysis was conducted on each of the open-ended response items. First, the data was analyzed using manifest coding and researcher-generated latent coding highlighting every possible perspective and theme revealed through the open responses. Next, all themes and perspectives were then uploaded, organized, and analyzed using a qualitative program called MAXQDA Pro.

The study was conducted in the states of Ohio and North Carolina during the close of the 2019-2020 school year. Although the questionnaire was initially intended to be distributed in March 2020, due to the COVID-19 pandemic, the researchers determined it best for the potential participants to delay the distribution until June 2020. The questionnaire was distributed via email to public school district school board members. The email addresses of school board members are publicly available. The researchers first attempted to locate the board president/chair's email contact information. However, if this information was not available, another board member was contacted. The recruitment email to the school board members included an invitation to participate in the study, a brief description of the study, and a SurveyMonkey link. When the participants accessed the SurveyMonkey link, they were presented with the Institutional Review Board (IRB) approved implied consent page which required acceptance to proceed with the questionnaire.

A total of 529 school board members were sent the recruitment email. From this request, 76 school board members chose to participate in this study. This is one limitation of this study. The researchers believe that if the questionnaire was administered without all of the ongoing, pressing issues attributed to COVID19 , there may have been increased participation. Of the participants $(\mathrm{N}=76)$ who responded to the demographic questions, most ( 89 percent) were school board members from Ohio while 11 percent were located in North Carolina. The majority of questionnaire participants were the board president/chair (65 percent). The number of years of service varied with over half of the study participants serving in the position ten years or less (64 percent). participants represented suburban (46\%), rural (45\%), and urban $(9 \%)$ districts with a majority (68\%) of all participant school districts having fewer than 4000 students. Ninety-four percent of the school board members reported they participated in superintendent evaluations for their school district.

\section{FINDINGS}

\section{Evaluation Criteria}

To answer the first research question, participants were asked "What criteria does your school board use to evaluate the superintendent?" In this open-ended response question, participants identified more than one criterion; therefore, using a thematic coding system was essential to quantify the occurrences of each type of manifested code in participant responses. The most frequent criteria school board members reported they use to evaluate the superintendent were performance-based goals (e.g., "goals and objectives set forth for the school year"). Most of the participants indicated the goals were set by the school board. For example, participants explained, "We set goals at the beginning of the year and evaluate based on data that supports the goals being met." Another response highlighted, "The board helps establish goals for the school year. Then we evaluate progress on goals." In many instances, the performance goals were created by the board in conjunction with the superintendent. These responses included: "an evaluation both board members and 
employee [superintendent] agree to in advance," and "a format agreed to by the board and the superintendent." In other instances, the work was more collaborative. One participant shared the "goals are established jointly by the superintendent and the board. Together we evaluate the progress during the past year and then establish new goals." Participants also mentioned other measurement criteria including the state framework (e.g. the Ohio Superintendent Evaluation System), community relations data, a written summary form, and the Ohio School Board Association (OSBA) workbooks (see Figure 1).

FIGURE 1

SUPERINTENDENT EVALUATION CRITERIA

\section{Community community relations established school year OSBA Personal evaluation school use work Board yearly goals stateSTANDARD staffyear performance evaluation form interaction staff $S$ uperintendent review $_{\text {. }}$

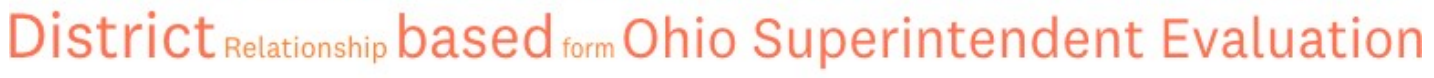

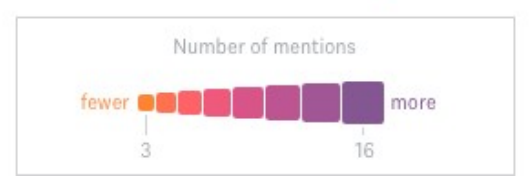

To further investigate the first research question (What criteria do school boards use to evaluate superintendents?), the participants were asked selected-response questions around the use of national standards, state standards, and the job description. Ninety percent of participant school board members reported they are required to evaluate their superintendent. However, only 26 percent of participants reported they utilize the Professional Standards for Educational Leaders (PSEL) to evaluate the superintendent. The school board members in this study reported they were more likely to use the superintendent job description (75 percent) and state standards (63 percent) as criteria to evaluate the superintendent. Interestingly, when participants were asked, "Does your school board use any of the following criteria to evaluate the superintendent (choose all that apply)?" the majority of participants reported they utilize the ten standards of the PSEL, although they do not identify these as the national standards. More than seventy-five percent of participants reported they use the following criteria to evaluate the superintendent: operations and management (98.57\%), curriculum, instruction, and assessment $(91.43 \%)$, mission, vision, and core values $(87.14 \%)$, meaningful engagement of families and community (82.86\%), school improvement (82.86\%), and ethics and professional norms (78.57\%). Fewer participants reported they use community care and support for students (70\%), professional community for teachers and staff $(67.14 \%)$, professional capacity of school personnel $(62.86 \%)$, and equity and cultural responsiveness $(57.14 \%)$ (see Figure 2). 


\section{FIGURE 2 \\ SUPERINTENDENT EVALUATION CRITERIA USED BY PERCENTAGE OF PARTICIPANTS}

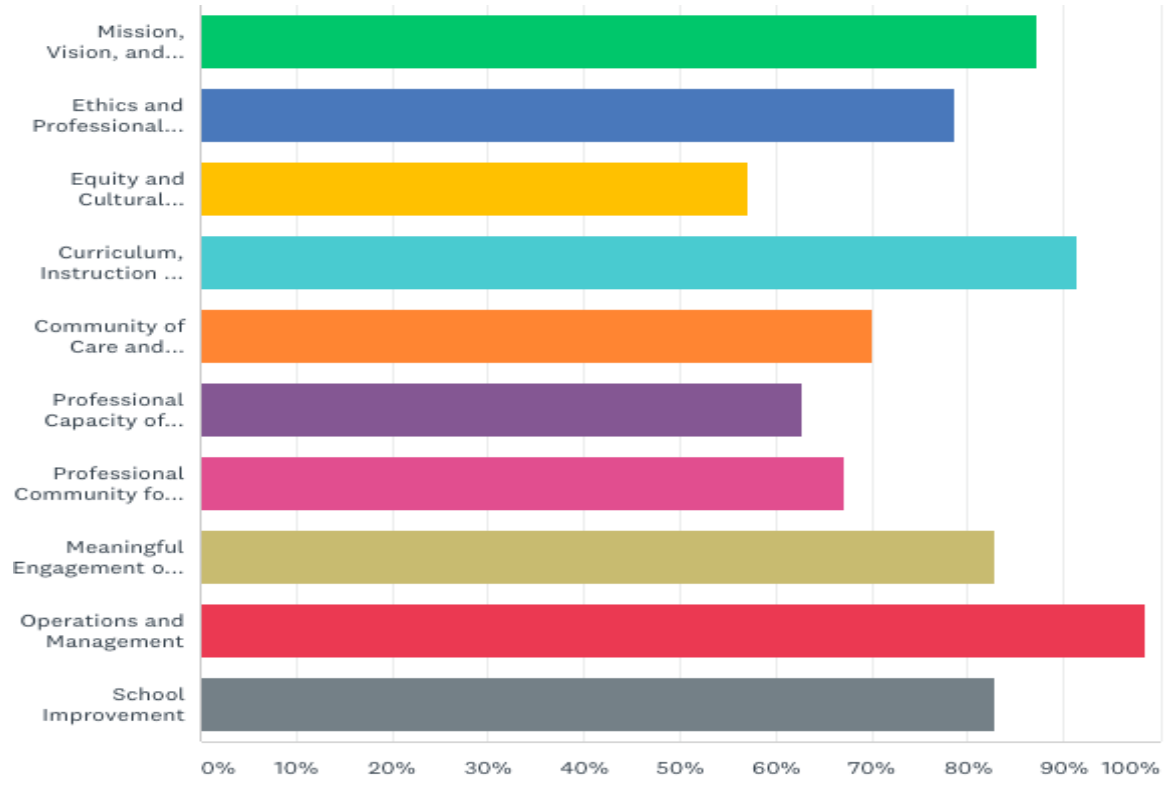

\section{Evaluation Procedures}

To answer the second research question, participants were asked "What procedures does your school board use to evaluate the superintendent?" In this open-ended response question, the most identified procedures were conducting an in-person or conference review of the superintendent. For example, one participant reported they conducted an "annual in person review with [the] President and Vice President listing areas of strengths, areas of improvement, and review of goals set." Another participant noted, the "superintendent does a self-evaluation. Then the board uses that info plus observations to evaluate superintendent." Other responses included holding a closed board discussion (e.g., "we meet in executive session as a mini work session"), the board completed a survey, or the board completed a comprehensive worksheet. Open-ended responses also provided insight into some board members' frustration with the procedures with the evaluation process. One participant noted, "None, it's disgusting." Another explained "complete an incomprehensible worksheet, discuss, vote, and the 5he (sic) mean." A third participant cantankerously responded, "Are we required to evaluate the Superintendent? By whom? Bad question. Do we use state standards? What state standards? Law? There are none."

To further investigate the second research question (What procedures do school boards use to evaluate superintendents?), the participants were asked the open-ended response question "What data sources are used to evaluate the superintendent?" The most frequent data sources reported were the state report card, observable and collected evidence, annual goals, school board input, and none (see Figure 3). Among the most poignant responses where those that spoke to the lack of data used in superintendent evaluations. For example, one participant answered frankly "none, it's all opinion based with no data, it's a popularity contest." Another participant simply stated, "This evaluation is not data driven." Other responses confirmed the widespread lack of data usage, including "don't use them," "no data soures (sic). Each board member does their own process," "none," "I don't know," and "not sure what you mean in regard to data??" The same participant who responded to question seven with "What state standards? Law? There are none" responded to question eight with "Data sources? You have to be kidding." Subsequent answers to other questions on the survey suggested this response indicated the use of data in superintendent evaluation was completely unnecessary. 
FIGURE 3

SUPERINTENDENT EVALUATION DATA SOURCES

\section{observations measures state testing form board Annual board member superintendent evaluation support

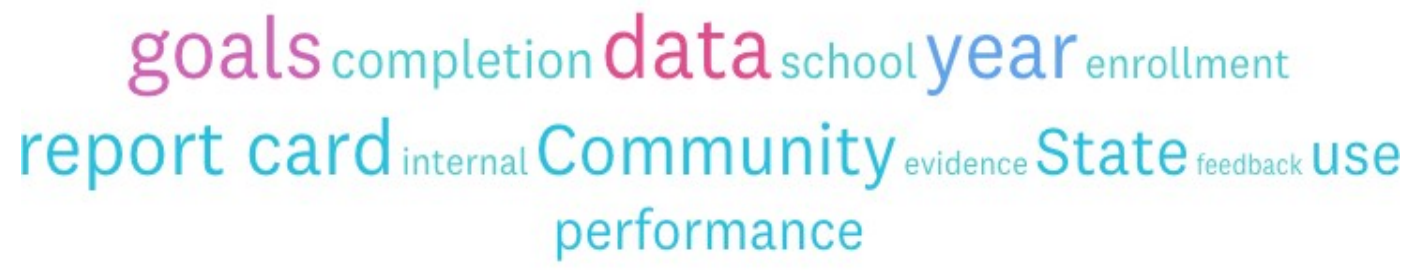

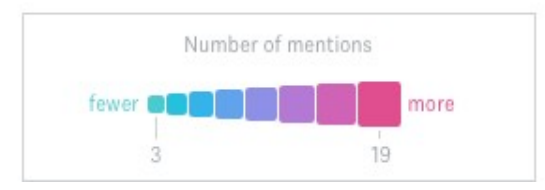

Participants were also asked "How are the data sources collected to evaluate the superintendent?" Almost half of the participants reported data is collected from the superintendent and/or leadership team. The other ways identified in which the data sources were collected to evaluate the superintendent included board member input, an interview or meeting, community-provided data sources, school-provided data sources, and state report card data. Thirteen percent of participants reported they do not use any data. The cantankerous participant who responded to question seven "What state standards? Law? There are none" responded to this question: "LOL" (a.k.a., laugh out loud), suggesting the usefulness of data collection for superintendent evaluation in their district was laughable.

Participants were then asked selected-response questions around the use of specific procedures used to evaluate superintendents including document review, performance goals, and a rating scale. More than half of participants (53\%) reported document review was used to evaluate the superintendent. However, $27 \%$ of participants reported document review was not used to evaluate the superintendent and $20 \%$ of participants reported document review was not applicable. Almost all participants $(90 \%)$ reported performance goals were used to evaluate the superintendent and $74 \%$ of participants reported a rating scale was used to evaluate the superintendent. The majority of participants $(94 \%)$ reported an established timeline was used to evaluate the superintendent which is annual (75\%). Ninety-six percent of the respondents reported an outside facilitator is not used to evaluate the superintendent.

\section{Professional Development}

For the third research question, in response to the open-ended question, "What professional development does your school board use to learn how to evaluate superintendents?" many participants stated they received Ohio School Board Association (OSBA) professional development through their conferences, while other participants state they receive guidance from the state department of education and other districts (see Figure 4). Some participants responses reflected individualized training in which board members gathered data to train themselves. Some of these responses included "read other surveys and to decide what we find important," "it is up to each board member on what factors they use," "online reading and webinars," and "I have not had a professional development, just 30 years in education." Some responses indicated board members trained each other, for example "we meet and discuss," "members with more experience explain the process to newer members," and "none." The former president (me) did a lot of research and provided suggestions. That's the only thing." As with the previous open- ended questions, participants who reported no training and feeling jaded about the process provided the most striking responses. One shared, "Again, you're kidding, right? There's nothing magic about evaluating a 
superintendent. I've been evaluating employees for over 40 years now. In my experience, PD is typically worthless."

The next open-ended response question asked, "How often are your school board members trained on how to evaluate the superintendent?" More than half of the participants reported school board members were not trained on how to evaluate the superintendent. Some of the participants reported school board members were trained annually and other participants suggested that only new school board members were trained. A few participants acknowledged they would benefit from more training: "not as often as we should be" and "we haven't done any formal training, but it would be a good idea." One participant noted inconsistency in training across the school board: "Three of us normally go to conferences twice a year...two members have never been to...training." The most outspoken participant provided a justification why he/she believed training and data sources were laughable. He/she stated "Why would we need training? We all have plenty of private sector experience with employee evaluations." The participants were also asked, "Who trains the school board members on how to evaluate the superintendent?" The most frequent responses included no one trains the school board members how to evaluate the superintendent followed by OSBA and past or current board members. Ninety percent of participants reported they are not required to receive training to evaluate a superintendent.

Finally, participants were asked, "What topics have you received professional development on?" Seventeen percent of the participants reported they have received no professional development. Fifteen percent of the participants reported they received professional development on school law or other legal issues and $13 \%$ on OSBA. However, participants most frequently reported a wide variety of individual professional development topics. Other participants suggested they had completed a multitude of trainings with responses such as "an abundance of professional development training," "too numerous to count," "the list is LONG," and "they span the spectrum."

FIGURE 4

\section{SUPERINTENDENT EVALUATION PROFESSIONAL DEVELOPMENT}

\section{board members districts conferences superintendent Ohio School Board workshops none system OSBA years School Board Association experience Training use Private Consultant Education}

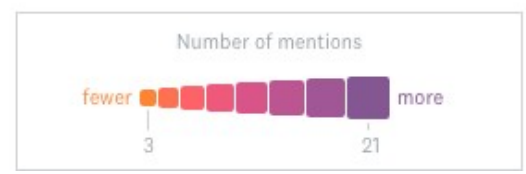

\section{Superintendent Evaluation Use}

For the fourth research question, the majority of participants reported the superintendent evaluation is used to guide discussions about goals. Most participants reported the evaluation is used for more than one purpose such as to guide a discussion on the progression of the superintendent in meeting their goals, to determine raises or monetary compensation, contract renewal decisions, and for self-reflection by the superintendent. There were some participants (6\%) that reported no use for the evaluation (see Figure 5). One participant stated: 
We don't. The majority of the board has the power, if they like the Superintendent, they make the evaluation fit their agenda. Nobody cares about the students, staff or community. In the past, it's been about the current board President having control. Our new board president has changed all of this and isn't putting up with it. The board hides all of the superintendent's misgivings, ethics violations, law breaking, etc. It's disgusting.

The wide variation in how the superintendent evaluation is used for both short-term as well as longterm planning aligned with the variations identified in the criteria, procedures, and professional development of participants.

\section{FIGURE 5 SUPERINTENDENT EVALUATION USE}

establish bonus improve future goals compensation provide feedback used review improvement contract superintendent new goals tool determine goals next year areas determine employment district $_{\text {use evaluation }}$ set $_{\text {board }}$ raises performance

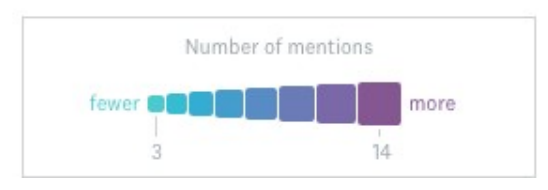

\section{DISCUSSION}

This study has immense significance for the researchers to address the marginalization of the empirical research and knowledge related to how school boards evaluate superintendents. Based on the analysis of the data, the researchers learned that in both these participating states, the school boards are required to evaluate their superintendent which aligns with the previous literature (Cleveland et al., 2000). However, school boards do not name the utilization of the Professional Standards for Educational Leaders (2015) for superintendent evaluation, even though the majority of respondents reported they use the ten standards as criteria. The school boards were more likely to use the superintendent job descriptions in the evaluation with the purpose of discussing the superintendent's goals.

A majority of participants reported that superintendents are evaluated once per year and the most common procedures were in-person or conference review with the superintendent. The

data most collected by school boards for evaluation purposes included the state report card and observable and collected evidence. The superintendent and the school board served as the most common source of that data with only a small amount of data originating with the community. A significant number of participants revealed they do not use data in their evaluations. The open- ended responses provided some of the richest insight into evaluation procedures. Participants who did not use data responded with a mixture of contempt for data and "disgust" at the lack of data. A lack of data for evaluations is concerning since prior research has noted that school often lack understanding about the educational responsibilities of the superintendent (DiPaola, 2007) and the difficulty in properly assessing superintendents in light of that lack of understanding (Weber, 2007).

In addition, $90 \%$ of respondents reported they are not required to receive training to evaluate a superintendent. These findings support previous literature (DiPaola et al., 2019; DiPaola \& Stronge, 2001; 
Glass, 2000; Cleveland et al., 2000) in that the use of superintendent job descriptions and the resulting goals are primarily designed by the school board with little if any input from other groups which is apparent in the lack of professional development. The superintendent's relationship with the school board is therefore a persuasive indicator of whether the superintendent will be successful in their position (Bridges et al., 2019; Melton et al., 2019; Yates \& Jong, 2019). The literature indicates that school boards often rely upon superintendents themselves for direction on how to evaluate the superintendent (Cleveland et al., 2000; Glass et al., 2000; Goens, 2009; Jackson, 2016). Participants in this study also indicated that evaluation was influenced by the superintendent though responses most often indicated the superintendent contributed to the evaluation design, rather than designing it outright. This suggests that school boards are becoming more assertive and relying less on the superintendent for their evaluations. Participants reported superintendent evaluations were most commonly used for measuring superintendent performance goals and for purposes of compensation and contract renewal. Previous research indicates half of superintendents' nationwide report that evaluations ensure systemic accountability and establish performance goals (Glass et. al., 2000), yet only $66 \%$ of the superintendents reported they felt their evaluation procedures were fair Cleveland et al. (2000).

Although state and national superintendent standards are becoming more prevalent, the findings indicate superintendent evaluation is still highly idiosyncratic and dependent upon the practices of the local school board. There persists a lack of uniformity in the criteria, procedures, and uses of superintendent evaluations. The majority of superintendents in this study were evaluated upon a set of criteria developed between the school board and the superintendent rather than national or state standards. This study partially relied upon a phenomenological approach to examine superintendent evaluations through the lens of the school board member, a perspective which researchers had yet to explore. This approach revealed disparate attitudes among participants regarding training and professional development. These attitudes, combined with the lack of school board understanding of the role of the superintendent (DiPaola et al., 2019; DiPaola \& Stronge, 2001; Weber; 2007), suggest the effectiveness of superintendent evaluation varies widely from place to place. Researchers and policy makers must work together to ensure uniform, high quality superintendent evaluations that result in greater achievement and positive outcomes for students.

As a result of this study, the researchers recommend school boards intentionally name and utilize national standards such as the Professional Standards for Educational Leaders [PSEL], (2015) as well as state standards in the criteria for superintendent evaluation. Furthermore, school boards should institute superintendent evaluation procedures more aligned to these criteria as well as the procedures recommended by the Joint Committee on Standards for Educational Evaluation [JCSEE], (2009). Professional development on the standards-based criteria and the procedures should be. Finally, the results and underlying purposes of the superintendent evaluation must be utilized more than simply to create professional goals for the superintendent. Superintendent evaluations should be more representative of the accountability era and standards-based teacher and principal evaluations. This would encourage a less subjective and more student-centered superintendent evaluation which is fundamental to the future success of all educational stakeholders.

To support this process, and because the literature on superintendent evaluations is limited, there is significant need for further research. Scholars need to determine how school boards perceive superintendent evaluation is similar and different from evaluating employees in other fields. Further research is also needed to explore the quantity and quality of professional development available to school board members. As superintendents have historically reported that performance-based evaluation criteria often don't match their actual job responsibilities (Bell, 2019; DiPaola \& Stronge, 2001; Kowalski, et al., 2011; Mayo \& McCartney, 2004), further research is needed to determine the alignment between the performance-based goals developed for superintendent evaluation and their relevance to actual job performance.

Participants in this study reported that they use criteria found in the PSEL standards, though they don't reference the PSEL standards themselves as a component of the evaluation. Further research will be needed to determine if the common criteria were adapted from PSEL, or if they originated from another source. The possible role of non-board member stakeholders in the evaluation process also warrants further study. 
Research into any effects the size or type of school district may have on superintendent evaluation as well as the role the board president/chair plays in comparison to other school board members is also needed.

\section{REFERENCES}

Bell, J.J. (2019). Superintendent job satisfaction in an era of reduced resources and increased accountability. AASA Journal of Scholarship \& Practice, 16(3), 38-55.

Bridges, K., Plancher, A.K., \& Toledo, S.D. (2019). Good governance and the influence of the superintendent. AASA Journal of Scholarship \& Practice, 16(2), 35-42.

Cleveland, P., Petersen, G.J., Sharp, W.M., \& Walter, J.K. (2000). A three-state examination of school board evaluations of superintendents. Educational Research Quarterly, 23(3), 3-21.

DiPaola, M., \& Stronge, J.H. (2001). Superintendent evaluation in a standards-based environment: A status report from the states. Journal of Personnel Evaluation in Education, 15, 97-110.

DiPaola, M.F. (2007). Revisiting superintendent evaluation. School Administrator, 64(6), 18-22.

DiPaola, M.F., Schneider, T.L., \& Staples, S.R. (2019). Evaluating school superintendents: A guide to employing fair and effective processes and practices. Rowman \& Littlefield.

Finnan, L.A., McCord, R.S., Stream, C.C., Mattocks, T.C., Petersen, G.J., \& Ellerson, N.M. (2015). Study of the American superintendent: 2015 Mid-decade update. Rowman \& Littlefield Education.

Glass, T., Bjork, L., \& Brunner, C. (2000). The study of the American school superintendency, 2000: A look at the superintendent of education in the new millennium. Rowman \& Littlefield Education.

Goens, G.A. (2009). Evaluating the superintendent. The American School Board Journal, 9(196), 24-26.

Henrikson, R.H. (2018). Superintendent evaluation frameworks for continuous improvement: Using evidence-based processes to promote the stance of improvement. AASA Journal of Scholarship \& Practice, 15(1), 22-29.

Jackson, L.A. (2016). Building and maintaining relationships between superintendents and school board members: The approach of two public school superintendents (Publication No. 47) [Doctoral dissertation, University of San Diego]. Digital USD Publishing.

Kowalski, T.J., McCord, R.S., Peterson, G.J., Young, I.P., \& Ellerson, N.M. (2011). The American school superintendent 2010 decennial study. Rowman \& Littlefield Education.

Maranto, R., Trivitt, J., Nichols, M., \& Watson, A. (2017). No contractual obligation to improve education: School boards and their superintendents. Politics \& Policy, 45, 1003-1023.

Mayo, C.R., \& McCartney, G.P. (2004). School superintendents' evaluations: Effective and resultsbased? ERS Spectrum, 22(1), 19-33.

Melton, T.D., Reeves, L., McBrayer, J.S., \& Smith, A.Q. (2019). Navigating the politics of the superintendency. AASA Journal of Scholarship and Practice, 16(3), 23-37.

National Policy Board for Educational Administration. (2015). Professional standards for educational leaders. Retrieved from http://npbea.org/wp- content/uploads/2017/06/Professional-Standardsfor-Educational-Leaders_2015.pdf

Robinson, K.K., \& Shakeshaft, C. (2016). Superintendent stress and superintendent health: A national study. Journal of Education and Human Development, 5(1), 120-133.

Schneider, T. (2018). A state-level superintendent evaluation policy analysis (Publication No. 1550153937) [Doctoral dissertation, College of William and Mary]. W\&M ScholarWorks.

Tienken, C.H. (2021). The evolution of the American school superintendent. In C.H. Tienken (Ed.), The American school superintendent: 2020 decennial study. Rowman \& Littlefield Education.

Weber, L.E. (2007). Evaluate me on measures, not tales. School Administrator, 64(6), 16.

Yates, S., \& Jong, D.D. (2018). Factors influencing rural superintendent tenure in a midwestern state. AASA Journal of Scholarship \& Practice, 15(2), 17-36. 